\title{
PRAGMÁTICA DE LA NARRACIÓN ORAL
}

\section{Cano-Manuel Díaz, Macarena}

\author{
IES Alminares \\ Departamento de Lengua castellana y Literatura \\ Avda de la Constitución s/n. \\ 11630 Arcos de la Frontera, Cádiz \\ E-mail: candiama@ono.com
}

\section{Resumen}

Actualmente asistimos a un importante desarrollo de la narración oral, materializada en la figura de los "narradores" o "cuentacuentos" quienes, tomando el relevo de los últimos juglares, centran su actividad literaria en la más pura y genuina narración de historias. Este trabajo se centra en la descripción y análisis de los elementos que intervienen en las sesiones de narración oral como práctica social. Adaptando al hecho literario de la oralidad los factores establecidos por Jakobson: emisor-narrador, receptor-público y así sucesivamente y atendiendo a los conceptos de la pragmática comunicativa, destacamos el papel fundamental y determinante de cada uno de los elementos en dicho proceso comunicativo.

Palabras Clave: narración oral, cuento, narrador, público, contexto

\begin{abstract}
Today we see a noticeable development of oral narration, centred on the role of the "narrator" or "storyteller", who taking the place of the traditional minstrel, focuses his literary activity on the storytelling in its purest and most genuine form.

This paper concentrates on the description and analysis of the elements that appear in oral narration as a social activity. By adapting the factors established by Jakobson (issuer-narrator, receptor-public) to the literary fact of oral genre and by examining the concepts of pragmatism of communication, we highlight the fundamental role of each of the elements of this communication process
\end{abstract}

Key words: oral narration, story, narrador, public, context

\section{Résumé}

Aujourd'hui on assiste à un développement très important de la narration orale représentée par les narrateurs ou les conteurs, qui, en prenant le relais des derniers jongleurs, font de la narration historique le point le plus important de leur activité littéraire.

Ce travail est centré sur la description et sur les analyses des éléments qui interviennent aux séances de la narration comme pratique sociale.

En adaptant les facteurs établis par Jakobson (émetteur- narrateur, récepteur- public ) au fait littéraire de l'oralité, et en faisant attention aux concepts de la pragmatique de la communication, on peut mettre en relief le rôle fondamental et absolument déterminant de chacun des éléments du processus de la communication.

Mots clés: narration orale, conte, narrateur, public, contexte.

Pragmalingüistica, 14, (2006), 25-32 


\section{Sumario}

1. Introducción. 2. El cuento: enunciación narrativa. 3. Contexto narrativo. 4. Relación narrador-público. 5. El cuento: un sortilegio de códigos. 6. El narrador y el cuento. 7. Epílogo. 8. Referencias.

\section{Introducción}

¿Qué tienen los cuentos para que aún hoy, en plena era de la comunicación virtual, de la imagen de fácil acceso, en pleno auge de la producción literaria específica para cada edad, sigan convocando incondicionalmente a niños, jóvenes y ancianos por el puro placer de escuchar historias de viva voz? La figura del narrador oral ha sido transferida durante décadas a la literatura escrita, donde no pocas veces lo descubrimos como personaje de ficción: Rashid, el contador de historias de la novela Harún y el Mar de las Historias de Salman Rushdie, la mítica Scherezade en Voces del desierto de Nélida Piñón, o el agente inmobiliario Rider, personaje excepcional de la novela de Daniel Wallace, El rey de la Sandía por citar algún ejemplo.

Actualmente nos encontramos ante un panorama literario donde la narración oral pura, "in praesentia", toma un nuevo auge. Siguiendo la tradición más antigua de juglares, trovadores, y goliardos, los cuentacuentos contemporáneos recorren pueblos, plazas, bibliotecas, colegios, salas, teatros y bares deleitando a un público sediento de historias.

Probablemente las motivaciones sean distintas que en la Edad Media, ya no buscamos noticias de otros lugares en los narradores, disponemos de cualquier obra literaria a nuestro alcance para leerla. Sin embargo compartimos la misma situación comunicativa de antaño: la edificación ante nuestros ojos y oídos de un castillo construido con palabras en el que es posible entrar y recorrer todos sus aposentos; la consumación de un acto oral vivo que abarca todo el proceso comunicativo completo que va desde la intención comunicativa previa del orador hasta la recepción por parte del público dentro de un marco referencial adecuado a dicha situación comunicativa.

\section{El cuento: enunciación narrativa}

Siempre había reclamado el derecho de contar lo que quisiese. El arte de narrar sólo maduraba moviéndose intrépido en medio del pantano de las palabras improvisadas.

\section{Nélida Piñón. Voces del desierto}

Si para Benveniste "antes de la enunciación, la lengua es solamente la posibilidad de la lengua", también podemos afirmar que antes de su enunciación, el cuento es solamente una posibilidad narrativa. Con la aparición del sujeto oyente en el marco enunciativo nace el cuento. Así, este sólo existe en el presente, en el momento de su enunciación, haciendo

1 Benveniste, L'appareil formel de l'énonciation, 1974, Vol. II, 80-83.

Pragmalingüistica, 14, (2006), 25-32 
su aparición estelar inscrito en un contexto real específico. Como cualquier otra enunciación, también los cuentos hablados se sirven de un contexto para existir, de un referente.

El narrador oral se mueve entre dos tipos de enunciación:

a) El perteneciente al mundo real

b) El relativo al mundo narrado o ficticio

Cada uno de ellos está caracterizado y diferenciado en el discurso por una deixis específica, es decir, tienen referentes contextuales y extratextuales diferentes: el primero, creado entre narrador y público, vendrá definido por deícticos adverbiales espaciales y temporales, mientras que el segundo queda definido por las marcas discursivas internas del cuento, que serán muy variables.

El narrador opera pues con dos sistemas o, más bien, con dos planos de enunciación separados en el discurso por sus correspondiente marcas discursivas, aunque contiguos lingüísticamente: el mundo real, dependiente del contexto físico inmediato y de la relación, no sólo entre los interlocutores, narrador y público, sino entre todos los elementos comunicativos en acción que envuelven al mundo narrado, al cuento.

El relato del mundo ficticio inmerso en tiempos verbales pretéritos, con sus correspondientes conectores: "ellos, allá, entonces..." que conforma un primer plano de enunciado frente al tiempo presente del mundo real y sus "nosotros, aquí, ahora" que conforma el segundo. En el primero predomina un lenguaje coloquial, con todas las características propias de la lengua hablada, comunicación directa dependiente de la situación comunicativa, frente al lenguaje literario del segundo donde el narrador luce sus artes verbales.

Obviamente en el acto de la narración oral, existe una jerarquía entre ambos planos. De hecho, el mundo real se convierte en una estrategia más del narrador para atraer la atención del oyente y que esta recaiga incólume sobre la historia narrada, objetivo y fin primordial del intercambio lingüístico y de la intención comunicativa de ambos interlocutores.

El narrador hará acopio de sus oportunas modalidades de enunciación, manifiestas a través de sus propias destrezas verbales, como recursos para lograr sus finalidades comunicativas. De este modo es determinante la actitud adoptada por el orador, sujeto enunciador, ante su historia enunciada, su cuento, y ante su interlocutor, el público al que va destinada.

\section{Contexto narrativo}

Mi abuelo no era nada salvo el montón de historias que había urdido sobre él y sobre el mundo.

\section{Daniel Wallace. El rey de la sandía}

Solamente en el seno de un contexto adecuado adquiere sentido el cuento de transmisión oral, en presencia de un destinatario capaz de recibir y descodificar el mensaje

Pragmalingüística, 14, (2006), 25-32 
literario. Y solamente así se materializa y adquiere sentido el cuento como unidad de comunicación semántico-pragmática. Así, desde la perspectiva de un enfoque integrativo, una sesión de narración oral es la manifestación de una actividad comunicativa en la que los roles de los interlocutores están claramente definidos y dispuestos por una práctica de comunicación social tan antigua y multicultural como el hombre.

Por todo ello, el contexto cobra un protagonismo singular en el desarrollo discursivo y la interpretación del cuento oral en el marco de un acto comunicativo de interacción real.

Entendemos "contexto" en sentido amplio, abarcando todas las posibilidades estudiadas por diversos lingüistas: tanto el situacional: entorno espacial, temporal y social; el lingüístico o co-texto: totalidad textual en la que se inserta el cuento y el cognitivo conjunto de saberes enciclopédicos, conocimiento del mundo y creencias, compartidos por los interlocutores presentes en tan peculiar acto de comunicación ya que todos ellos colaboran en la aportación necesaria para la descodificación e interpretación del cuento. Y además poseen el poder suficiente como para elevar la narración a niveles estelares o para hacerla añicos sin que el emisario parlante lo pueda evitar. De este modo el narrador queda eximido de gran parte de responsabilidad en el conjuro de los cuentos ya que no siempre el éxito depende directamente de él sino de otros factores, a veces azarosos, como el lugar donde se está narrando, la expectativa, los conocimientos, creencias y actitud del público, por citar algunos condicionantes.

El mismo relato, proveniente de una misma fuente y de una misma voz, varía pues dependiendo del contexto en el que se inserta. El silencio previo puede ser factor determinante así como la quietud del lugar, la luz, la disposición física del público y la visión óptica que este tenga del narrador. En este sentido, los espacios físicos donde tienen lugar los encuentros entre narradores y públicos son previamente dispuestos para la ocasión. Por ello, habitualmente precisan de la colaboración de terceras personas: técnicos culturales, bibliotecarios, profesores, etc.

\section{Relación narrador - público}

Cada noche Sherezade envuelve al califa en una tela sutil. Apacigua sus nervios, mientras que sus ritmos narrativos expresan la danza de los sentimientos. Sus historias sacian a los oyentes ávidos.

\section{Nélida Piñón. Voces del desierto.}

La historia se crea porque hay un público que escucha y la recibe y que participa en la arquitectura del entramado narrativo.

El contexto situacional predispone al público oyente a recibir o rechazar el mensaje literario. A su vez el narrador percibe esta actitud del receptor y, actuando en consecuencia, haciendo uso de la propiedad innata del lenguaje verbal de la retroalimentación, guiará su discurso oral en uno u otro sentido, bien retardándolo, recreándose en detalles nimios, seleccionando cuidadosamente sus palabras, introduciendo silencios, descripciones, etc., bien acelerando la acción narrativa, buscando la introducción de algún nuevo tema que

Pragmalingüística, 14, (2006), 25-32 
atrape la atención del receptor pero jamás dejará el relato a medias aún a sabiendas del escaso interés que despierta en el público y bajo el riesgo de quedarse a solas con su repertorio. No olvidemos que el público que asiste a una sesión de narración oral, salvo excepciones, es voluntario y exigente y que no transigirá ante un narrador que no esté a la altura de las expectativas, luego no tendrá ningún pudor en abandonar la atenta escucha creando ruidos que interfieran en el acto comunicativo e infundiendo mayor confusión al propio narrador al que le resultará aún más difícil remontar el espectáculo.

El oyente no pretende hacer un gran esfuerzo por seguir el hilo conductor del relato, solo contempla dos opciones: o se introduce en la historia relatada entrando a formar parte de ella o se ausenta. Si el narrador logra envolverlo en sus palabras habrá triunfado y podrá llevarlo a través de los increíbles vericuetos narrativos donde toda norma lingüística queda desplazada.

Narrador y oyente habrán creado un mundo fantástico por el que viajar a través de imágenes vivas descritas hábilmente por el efímero dueño de las palabras, el cuentacuentos. Si por el contrario el público no penetra en la "cueva de Aladino", repleta de tesoros verbales, el narrador fracasado habrá de servirse de estrategias narrativas y personales para salvar el espectáculo. Sin oídos donde recalar, no hay cuento. Tan solo un saco de voces arrojadas al vacío, precipitándose inexorablemente hacia la nada. El emisor de historias no habrá cumplido su función. La de conmover al receptor imponiéndole, momentáneamente, una nueva visión del mundo, haciéndole partícipe de ésta y aportándole nuevos conocimientos a su acervo imaginativo, bien transmitiéndole cuentos tradicionales relatados de boca en boca a través de los siglos, bien mostrando su propia visión del mundo a través de la recreación de su propio repertorio.

Entre narrador y público crean tácitamente un ambiente mítico, un contexto adecuado a la emisión y recreación de las historias narradas. Se va tejiendo, al hilo de las palabras, un cadena que los vincula íntimamente durante el breve tiempo que dure el relato hablado. Un tiempo que, por cierto, nada tiene que ver con las horas o los días sino que, al contrario, escapa a estos. Se trata de un tiempo sin medida, podríamos llamarlo sensación atemporal.

\section{El cuento: un sortilegio de códigos}

...cuando están hambrientos engullen cuentos por todas sus bocas y entonces, en su estómago, ocurren milagros...

\section{Salman Rushdie. Harún y el mar de las historias}

Cuando nace esta alianza tácita parece que todos los elementos de la comunicación se convocan en un lugar determinado, un entorno específico - un bar, una noche de verano en una pequeña placita, una biblioteca, etc- y cada uno de ellos brilla por sí mismo: narrador, público, cuento, códigos lingüísticos y paraverbales, aire y contexto hacen un despliegue singular de fuerza comunicativa. El acto comunicativo cobra vida propia, toma cuerpo e impregna con sublime existencia el espacio donde nacen, crecen y mueren las

Pragmalingüística, 14, (2006), 25-32 
historias. La magia de las palabras surge al consumarse la comunión de todos los factores comunicativos en juego. Y ya que "un maestro del cuento tiene que ser ducho en el arte de la interpretación: movimiento, gracia, voz y dicción"², toda una gama de códigos no verbales, habitualmente cargados de emotividad y afecto, y con predominio absoluto de la función expresiva de lenguaje, subyacen y apoyan la transmisión del mensaje narrativo causando algún tipo de efecto en el público: gestos, cercanía o lejanía, miradas, conductas imitativas, todos ellos lenguajes inherentes al texto que cobran sentido dentro de la situación comunicativa en la que se desarrollan.

Los sugerentes signos faciales del narrador dan mayor fuerza y realzan los sentimientos de los personajes y de los mismos interlocutores sumidos ya en la historia. El cuentacuentos, con sus gestos, unidos irrevocablemente a sus palabras, deja testimonio de la evolución emocional de la historia: sorpresa, miedo, alegría, angustia, ira, cólera, felicidad, tristeza se reflejan en su semblante. Un buen narrador es capaz de estremecer tanto con la mirada como con las palabras, de amenazar tan solo levantando un dedo y teniendo por aliado al silencio, de hacer sonreír articulando sonidos sin significado aparente (segregaciones vocales para Trager) y lograr que todas estas señales audiovisuales queden integradas en el texto oral. Así, el público también puede ir haciendo una lectura paralela del cuento en el expresivo rostro del narrador.

Pero no sólo el semblante del orador va transcribiendo el cuento a la par que las palabras, también este va acompañado de los movimientos acompasados del cuerpo del narrador quien lo utiliza para causar impresiones en el espectador. "El instrumento del narrador lo compone todo su cuerpo" . Se acerca o se aleja de éste persiguiendo alguna intención comunicativa concreta: custodiar el susurro de un personaje, crear inquietud en el ambiente o buscar la complicidad del público. De modo que no sólo las palabras comunican, también un sinfín de códigos paraverbales todos ellos bien conocidos y ejecutados por el narrador.

\section{El narrador y el cuento}

Los cuentos calman, despejan; acunan o espabilan, agudizan el discernimiento y el ingenio. Contar cuentos es una actividad pacifica y revolucionaria.

Estrella Ortiz. Rotundifolia: contar con los cuentos.

El narrador se sumerge en su propia memoria, continente de sus cuentos, y éstas, vivas, haciéndole creer que las elige, brotan a la luz por sí mismas. El narrador es solamente un medio para que esas historias vivan, se expandan entre los oídos de los oyentes y formen parte de su más profundo conocimiento del mundo y de sus más íntimas creencias. Los cuentos una vez que colman el canal comunicativo, en este caso el aire, ya no pertenecen

2 Fragmento de "Notes from a Conversation at Doc Willy's Bar", grabada por Bob Jenkins. 1984 Steve Safield. Citado en Mujeres que corren con los lobos" p. 541.

3 Estrella Ortiz: Rotundifolia: contar con los cuentos, Guadalajara, Naque, 2002. p. 71.

Pragmalingüística, 14, (2006), 25-32 
al contador de historias. Las ha regalado y, debido a la fugacidad de la palabra hablada, que no perdura en el tiempo, ya no las posee. Tendrá una igual pero no esa que contó ese día en ese espacio y momento. Así lo cuenta Salman Rushdie:

“...cuando escupen los cuentos, ya no son cuentos viejos, sino nuevos. Nada sale de la nada, no hay cuento que surja del aire; los cuentos nuevos nacen de los viejos" $"$.

Como dice G. Green, "el acto comunicativo es un acto de fe" y así lo sienten el narrador y el espectador, ambos asisten al ritual de las palabras persiguiendo un mismo fin: dejarse atrapar por las historias, introducirse, vivirlas y crecer en ellas. Escapar durante un tiempo indefinido de su realidad cotidiana para penetrar en otra erigida verbalmente en su presencia. Asistir al trance creativo del mundo mágico de los cuentos. El narrador, creador de ilusiones verbales, goza con la intención comunicativa de guiar al receptor por el camino que le lleva a esa frontera entre la realidad y el relato oral. Por ello no suele entrar directamente en el cuento. Comienza la oratoria cuentística con un intento de acercamiento al público para despertar sus oídos y estimular su imaginación. Y, haciendo gala del Principio de Cooperación de Grice, cada narrador posee su propio rito, su propio saludo de iniciación. Así el acuerdo previo que sostiene la comunicación verbal viva queda sellado. Una vez afianzada la expectativa del público, el silencio es un campo donde arar los cuentos. El narrador muestra otra visión diferente del mundo, fantástica, donde su interlocutor se reconoce. Se sirve de las palabras, de las oraciones bien construidas pero también de otros recursos no lingüísticos como apelaciones directas al público o gestos, a veces del apoyo de algún objeto y siempre contará con la cooperación del oyente quien ha abandonado temporalmente su mundo real para entrar en otro ficticio a través de la caricia de la voz de un narrador, tal vez buscando otros significados del mundo, otros reinos, otros viajes, tal vez, simplemente, porque los cuentos están ahí, en los corazones, en las gargantas, en el aire. Como están las conchas en la playa, los tesoros de los barcos hundidos, los fantasmas de la noche, las hadas del bosque, los ogros, las sirenas, los unicornios y las medusas gigantes. Alguien los tiene que salvar.

\section{Epílogo}

... contar un cuento es el acto de amor más sublime que se puede ofrecer a un ser querido. Los amantes se cuentan cuentos para que el amor habite entre ellos y nunca los abandone. Es el conjuro más poderoso para ahuyentar cualquier hechizo que se pueda preparar para destruir el amor.

Xavier P. Docampo. Cuatro cartas.

\footnotetext{
4 Salman Rushdie: Harún y el mar de las historias, 1991, Seix Barral: p. 74.
}

Pragmalingüística, 14, (2006), 25-32 
De una sesión de narración oral no perduran testimonios escritos, pero sí dejan huella en los corazones de aquellos que son capaces de recibir y regocijarse con las historias contadas por otros.

A los narradores les debemos la supervivencia de una de las tradiciones más antiguas del hombre: el arte de contar cuentos y el poder seguir disfrutando de la calma y el placer de recrearse en la palabra. Ellos rescatan a los cuentos de algún lugar de la historia y del mundo para regalarlos a los oyentes. Las historias esperan silenciosas en el limbo de las palabras a que algún narrador las recoja, les infunda un nuevo soplo de vida y las divulgue por los oídos de quienes saben escuchar para que puedan perpetuar su camino a través del tiempo.

Este trabajo surge de la fascinación creada por la escucha de los cuentos, de una esmerada y atenta observación de lo narradores y narraciones de cuentos que me han acompañado desde la niñez.

A los narradores del sur: Pepe Maestro, Kiko Butrón y Juan José “el gorrión”.

\section{Referencias}

AUSTIN, J.L. (1962), Cómo hacer cosas con palabras. Barcelona. Paidós. (1998).

DOCAMPO XAVIER, P. (1998), Cuatro cartas. Madrid, Anaya.

ESCANDELL VIDAL, Ma V $^{\mathrm{a}}$. (2002), Introducción a la pragmática. Barcelona. Ariel.

HERRERO CECILIA, Juan (2006), Teorías de pragmática, de lingüística textual y de análisis del discurso. Ediciones de la Universidad de Castilla-La Mancha. Colección Monografías $n^{\circ} 49$. Cuenca.

KNAPP, M.L. (1982), La comunicación no verbal. El cuerpo y el entorno, Paidós. Comunicación, Barcelona, (1992).

ORTIZ, Estrella (2002) Rotundifolia: contar con los cuentos, Guadalajara, Naque.

PIÑÓN, Nélida, (2005), Voces del desierto, Madrid, Alfaguara.

PORTOLÉS, José, (2004), Pragmática para hispanistas. Madrid: Síntesis.

REYES, Graciela (1995). El abecé de la pragmática. Cuadernos de Lengua Española nº 23, Arco / Libros. (2000).

RUSHDIE, Salman (1990) Harún y el mar de las historias, Barcelona, Seix Barral: Biblioteca Breve.

VAN DIJK, T.A. (1995), Texto y contexto: semántica y pragmática del discurso. Madrid, Cátedra.

Pragmalingüística, 14, (2006), 25-32 